\title{
Mathematical Model for Estimation of Hydroform Pressure \& Coefficient of Friction in Tube Hydroformed Parts
}

\author{
S.S.Ghorpade, S.H.Gawande \\ (Department of Mechanical Engineering, M.E.S. College of Engineering, S.P. Pune University, India)
}

\begin{abstract}
Hydroforming process has increasing demand in automotive and aerospace industry. As the demand of this technology or process increasing gradually it requires the proper research and development on all aspects in hydroforming process. Hydroforming pressure and coefficient of friction between (COF) tube and die are important parameters in hydroforming process. This paper presents results which were obtained by implementing the early developed mathematical models for estimation of hydroformig pressure[2]and COF [4] on T-Shaped tube hydroformed parts. By applying corresponding formulae hydroform pressure required and COF between hydroformed part and die is determined by using analytical and numerical approach. The results obtained from analytical and numerical approach are compared.
\end{abstract}

Keywords - Tube hydroforming, Hydroformig pressure, Coefficient of friction (COF), MS Excel, MATLAB

\section{INTRODUCTION}

Tube hydroforming (THF) has been called with many different names depending on the time and country it was used and investigated. Bulge forming of tubes (BFTs), liquid bulge forming ( LBF), hydraulic (or hydrostatic) pressure forming, internal high pressure forming (IMPF) were earlier terms used by different researcher and manufacturers. Even though THF process is practically used by industry from more than ten years, development of technology and its theoretical study is goes back to 1940s. THF process is forming process in which tubes are placed between pair of metal dies and applying hydraulic pressure to the inside of the tube. The sequential operations of THF process is shown in Fig.1. In order to avoid thinning of tube and wrinkling effect axial compressive force is applied during process to the both ends of tube. Advantage of hydroforming involves potentially reduced tooling cost, reduced finishing cost on formed parts, excellent material utilization, fewer operations and improved part quality. Also using THF process manufacturers are able to produce complex shaped parts with light weight and fewer welds. In the application of THF to the manufacturing of automobile components, It is often the case that the shape of the dies are so complicated that a tube in its original straight shape doesn't fit into the dies and it undergoes preforming work for bending and for partially flattening before the THF process. Post processing applications like piercing, welding can be done in hydroforming process. The knowledge of THF process parameters viz. process control parameters and tube material add benefits to quality of hydroforming process. Force or stroke controlled are the two major type of THF process. There are two stages in THF process viz. free forming and calibration. During deformation of tube when the tube expands without tool contact is known as free forming zone and when tool contact is developed the calibration starts. The free forming and calibration zones are shown in Fig.2.

A.

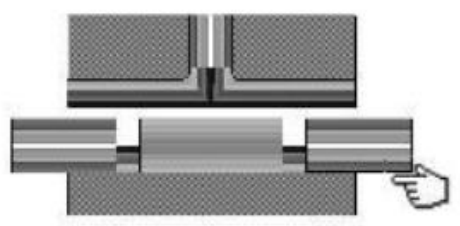

B.

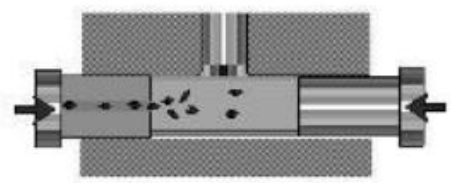

C.

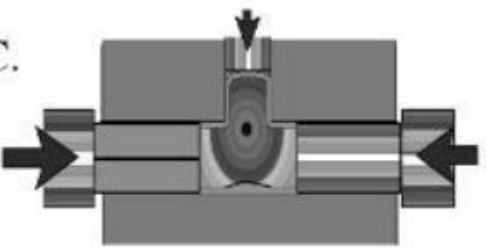

D.

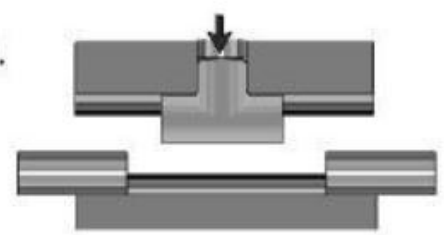

Fig.1.Sequential operations in hydroforming process. 


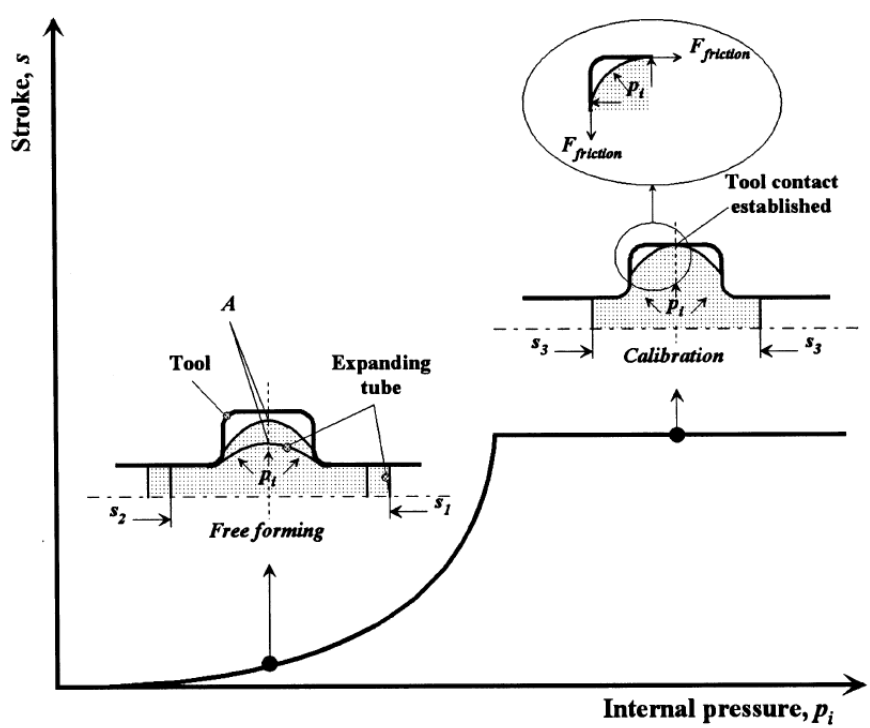

Fig.2. Free forming and calibration zone.

Now a days THF is widely used manufacturing process since process can manufacture any complex shapes. The hydroformed parts have very optimum weight to stiffness ratio having a good accuracy. THF process is mainly depend on the range of hydrofoming pressure, contact between two surfaces and process is characterized by the development of large friction forces between die and tube. This process is badly affect the process parameters and quality of the component. Hence to reduce this hostile effects it is necessary to reduce the friction in THF process. Using the value of COF one can perform the analysis of THF by using FEM. As the hydroforming process is one the growing technology many researchers are studied and work on this phenomenon from last 4 to 5 decades. The study of hydroforming process and various technological aspects like material selection, tribology and different process parameters was carried out by M. Koch and T. Alton [1] from early years to very recent years. Their study very useful for new researches and development. CoMParison of theoretical and experimental loading path in hydroforming process was presented by N. Asnafi [2] and A. skogsgardh . B. Screenivasulu and G. Prasanthi [3] carried out simulation of hydroforming process using DEFORM-3D solver and analyzed the effect of COF , axial compressive force and hydroform pressure on thickness variation based on upsetting a tube. F. Vollertsen and M. Plancak [4] developed a new mathematical model to measure a COF. They coMPared their obtained experimental results with FEM simulation results. To study the effect of loading path of hydroform pressure and axial feeding on hydroforming deformation $\mathrm{M}$. Mizumura [5] and his group carried different experimental tests and FEM analysis using simple geometry. M. Plancak [6] and his group developed a new analytical model for measurement of COF based upon the tube upsetting method. The purpose of their work was to study the tribological effect of different parameters on hydroforming process. The phenomenon of tube thinning and methods to avoid the defect at transition zone and stress distribution were explained by G. Liu [7] and group. Abrantes [8] and his group using LS-Dyna software studied the phenomenon of hydroforming process. They had taken aluminum tubes and two different process conditions in account for their study and coMPare simulation results with experimental results having same process conditions. To study the influence of the coefficient of friction and material properties on the thickness distribution H. Orban [9] and S.J.Hu developed analytical model. Their study is useful and providing a guidelines for structural tube hydroforming process. A. kocanda and H. Sadlowska[10] presented that hydroforming is one of the best method for development or manufacturing of component in automotive industry. Theoretical and experimental analysis of the axial force modeling in tube hydroforming is presented by E. Karabegovic [11] and his group in their work. As per literature survey and work done by many researcher it is observed that hydroform pressure and COF between tube and die are more important factors in hydroforming. This paper aims to study the different process parameters in THF such as hydroform pressure and coefficient of friction between outer surface of tube and die. The estimation and analysis of results for hydroform pressure and $\mathrm{COF}$ is presented in this paper. 


\section{PROBLEM OBJECTIVES AND PROCEDURE}

The presented work include

- Study of background of THF process and process parameters such as axial compressive force, hydroform pressure, clamping load on the die set and effective strain during the hydroforming.

- Study and analysis of the effect of different parameters on hydroform pressure and coefficient of friction.

- CoMParison of hydroform pressure obtained from numerical and analytical approach.

The following steps are followed to perform presented work

1. Literature Survey

2. Study of earlier mathematical models of hydroform pressure and coefficient of friction.

3. Implementation of modified mathematical model to earlier manufactured 'T-shaped' hydroformed part.

4. Estimation of hydroform pressure and COF using analytical and numerical approach.

\subsection{Mathematical Model for Hydroform Pressure}

\section{ANALYTICAL ANALYSIS}

3.1.1 Hydroform pressure at yielding.

Assume a tube is subjected to hydroform pressure $P_{i}$ and inward axial force, $\mathrm{F}$ as shown in Fig. 3. For an element at the centre of this tube, the hydroform pressure can be written

$$
\frac{\sigma_{1}}{\rho_{1}}+\frac{\sigma_{2}}{\rho_{2}}=\frac{P_{i}}{t_{i}}
$$
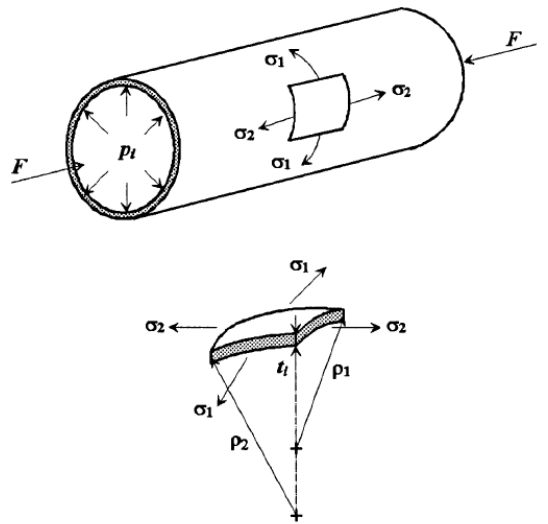

Fig. 3 Different stresses acting on the tube element at centre

Using Von Mises yield criterion the equation of plane stress and strain is written as follows:-

$$
\begin{gathered}
\bar{\sigma}=\left(1-\alpha-\alpha^{2}\right)^{1 / 2} \sigma_{1} \\
\text { and } \bar{\varepsilon}=\left[4\left(1+\beta+\beta^{2}\right) / 3\right]^{1 / 2} \varepsilon_{1} \\
\text { Where } \alpha=\frac{\sigma_{2}}{\sigma_{1}} \\
\text { And } \beta=\frac{\varepsilon_{2}}{\varepsilon_{1}}
\end{gathered}
$$

The tangential and radial strains $\varepsilon_{1}$ and $\varepsilon_{2}$, can be denoted as:

$$
\text { and } \quad \begin{aligned}
\varepsilon_{1} & =\ln \left(\frac{\rho_{1}}{\rho_{0}}\right) \\
\varepsilon_{3} & =\ln \left(\frac{t_{i}}{t_{0}}\right)
\end{aligned}
$$

Where $\rho_{0}$ is initial tube radius, $\rho_{1}$ is instantaneous tube radius, $t_{0}$ is initial tube wall thickness and $t_{i}$ is instantaneous tube wall thickness. 
The Levy-Misses flow rule (assuming volume constancy) :

$$
\alpha=\frac{(2 \beta+1)}{(\beta+2)}
$$

Or

$$
\beta=\frac{(2 \alpha-1)}{(2-\alpha)}
$$

Combining hydroform pressures. (1), (2) and (4), one can write

$$
p_{i}=\frac{\bar{\sigma} t_{i}}{\left(1-\alpha+\alpha^{2}\right)^{1 / 2}}+\left(\frac{1}{\rho_{1}}+\frac{\alpha}{\rho_{2}}\right)
$$

The above hydroform pressure is for elastic zone.

At the edge between elastic and plastic deformation (yielding line), one can write or assume that:

$$
\begin{gathered}
\rho_{1}=\frac{\left(d_{0}-t_{0}\right)}{2} \\
\rho_{2}=\infty \\
t_{i}=t_{0} . \\
\bar{\sigma}=R p 0.2
\end{gathered}
$$

Where $d_{0}$ is initial (Outer) tube diameter and $R_{p 0.2}$ is yield strength of the tube material.

Substituting hydroform pressures. (11)- (14) into eq. (10) yields:

$$
p_{i y}=\frac{2 R_{p 0.2} t_{0}}{\left(d_{0}-t_{0}\right)\left(1-\alpha+\alpha^{2}\right)^{1 / 2}}
$$

eq. (15) can be used for estimation of the yield limit.

\subsubsection{Hydroform pressure during plastic deformation.}

Assume that the tube expands in the fashion to form T-shape. This assumption means that $\rho_{2}=0$ with this assumption, hydroform pressure. (1) can be rewritten as

$$
\begin{gathered}
\frac{\sigma_{1}}{\rho_{1}}=\frac{p_{i}}{t_{i}} \\
\text { Combining } \rho_{1}=\frac{d_{i}-t_{i}}{2}
\end{gathered}
$$

Where $d_{i}$ is instantaneous tube diameter, with eq. 16), one obtains

Combining hydroform pressures. (2) and (18) yields

$$
p_{i}=\frac{2 t_{i} \sigma_{i}}{d_{i}-t_{i}}
$$

$$
p_{i}=\frac{2 t_{i} \bar{\sigma}}{\left(d_{i}-t_{i}\right) \sqrt{1-\alpha+\alpha^{2}}}
$$

Assume that the tube material obeys the Ludwik- Hollomon hardening relationship

$$
\bar{\sigma}=k(\bar{\varepsilon})^{n}
$$

Combining hydroform pressures. (3) and (20) with hydroform pressure. (19), one obtains

Substituting

$$
p_{i}=\frac{2 t_{i} k \varepsilon_{1}^{n}}{\left(d_{i}-t_{i}\right) \sqrt{1-\alpha+\alpha^{2}}}\left(4 \sqrt{\frac{\left(1+\beta+\beta^{2}\right)}{3}}\right)^{n}
$$




$$
\varepsilon_{1}=\ln \left(\frac{\rho_{1}}{\rho_{0}}\right)=\ln \left[\left(d_{i}-t_{i}\right) /\left(d_{0}-t_{0}\right)\right]
$$

and hydroform pressure. (9) into hydroform pressure. (22) yields

$$
p_{i}=\frac{2 t_{i}}{d_{i}-t_{i}} * k *\left(\frac{2}{2-\alpha}\right)^{n}\left(\sqrt{1-\alpha+\alpha^{2}}\right)^{n-1}\left(\ln \frac{d_{i}-t_{i}}{d_{0}-t_{0}}\right)^{n}
$$

An hydroform pressure (23) gives instantaneous pressure in plastic zone. Assume now,

$$
\varepsilon_{1}+\varepsilon_{2}+\varepsilon_{3}=0
$$

Hence combining hydroform pressures (5)-(7) and (17) with hydroform pressure (24), we can write:

$$
t_{i}=t_{0}\left[\left(d_{i-} t_{i}\right) /\left(d_{0}-t_{0}\right)\right]^{-(1+\beta)} \cong t_{0}\left(\frac{d_{i}}{d_{0}}\right)^{-(1+\beta)}
$$

Using hydroform pressure (25) one can find instantaneous thickness of tube.

\subsubsection{Maximum hydroform pressure limit.}

Maximum hydroform pressure is can be determined by following eqn:

$$
\left(p_{i}\right)_{b}=\sigma_{u}\left(\frac{4 t_{0}}{D_{0}-t_{0}}\right)
$$

Where $\sigma_{u}$ is ultimate strength of material.Hence using above hydroform pressures (15), (23) \& (24) we obtain a hydroform pressure.

\subsection{Mathematical model for coefficient of friction (COF)}

In THF process the flow of material during deformation is depend on the friction between tube and die. Frictional conditions are constantly changing during the THF process. There are three different zone in tube hydroformed part as shown in fig.4 viz. guided zone, transition zone and expansion zone. For the estimation of $\mathrm{COF}$ in THF process it is necessary to consider friction in above mentioned zone.

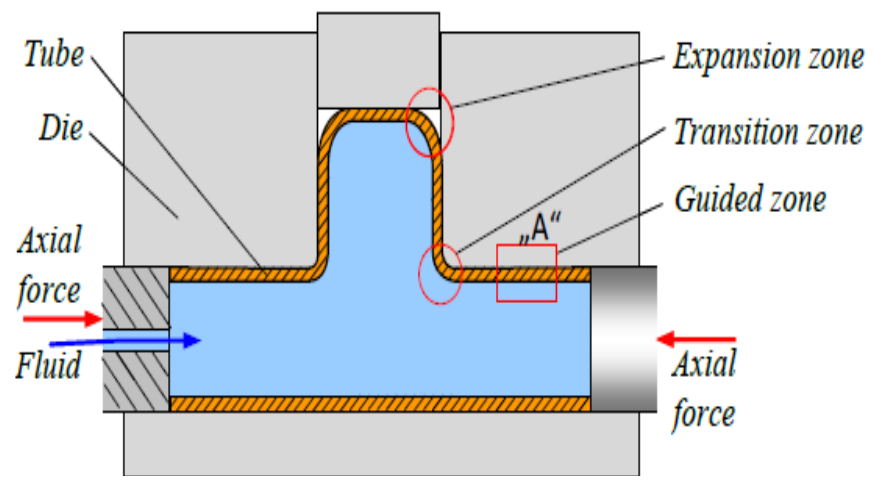

Fig. 4. Different zone in hydroforming process.

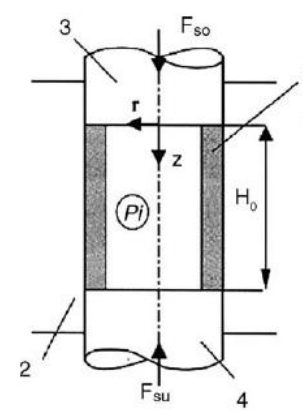

(a) initial Position

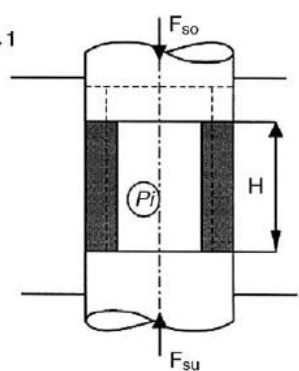

(b) without friction $[\mu=0]$

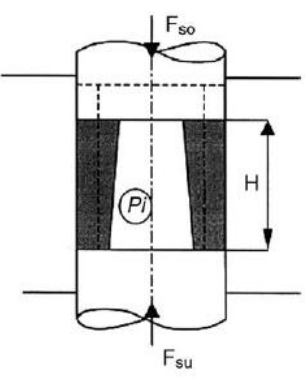

(c) with friction $[\mu \neq 0]$

Fig .5. Tube hydroforming Process 


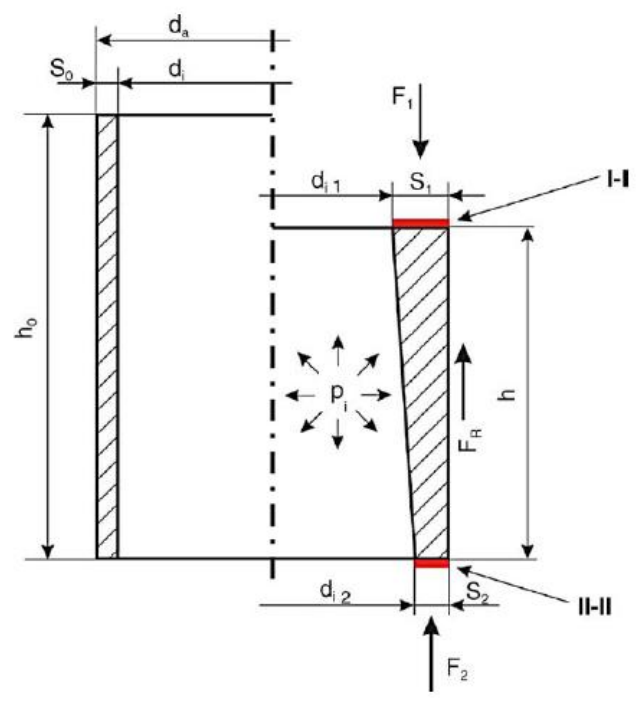

$F_{1}$ : Upsetting force,

$F_{2}:$ Reaction force,

$F_{R}$ : Friction force at the tube/die wall,

$S_{0}$ : Initial wall thickness,

$S_{1}$ : Wall thickness at the side of movable punch,

$S_{2}$ : Wall thickness at the side of fixed punch,

$d_{a}:$ Initial outer diameter of the tube,

$d_{i}$ : Initial inner diameter of the tube,

$d_{i 1}$ : Final inner diameter of the tube at the side of movable punch,

$d_{i 2}$ : Final inner diameter of the tube at the side of fixed punch,

$h_{0}:$ Initial height, and

$h:$ Final height.

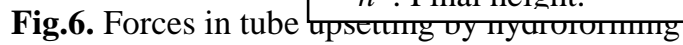

The construction of tube upsetting method is shown in fig.5. In this setup tube is placed in die and subjected to the hydroforming pressure, inward axial forces from both end viz. $F_{S O}$ is top end force and $F_{S U}$ is bottom end force. During process if friction is zero the deformation of tube is uniform along its height. In reality there is no such condition of zero friction so deformation nature of tube is non uniform.Under frictional condition the hickness of tube is maximum at top end side and minimum at bottom end side. Analysis is carried out by assuming following conditions :-

- Even distribution of friction stress along length of tube

- Axial stress and z-coordinate are dependent

- Uniform wall thickness distribution

- Coulomb law of friction is used

- Tresca's criterion is considered

Balancing of force in vertical direction is shown in fig. 6

$$
\begin{aligned}
& F_{1}=F_{2}+F_{R} \\
& F_{R}=\pi d_{a} h \mu \sigma_{k}
\end{aligned}
$$

Where $\sigma_{k}$ is contact stress between the work piece and the die.

Forces $F_{1}$ and $F_{2}$ written as:

$$
F_{1}=A_{1} \sigma_{1}
$$

Where

$$
\begin{gathered}
\sigma_{1}=\beta \sigma_{\text {eff } 1}+p_{i} \\
A_{1}=\frac{\pi}{4}\left(d_{a}^{2}-d_{i 1}^{2}\right) \\
F_{2}=A_{2} \sigma_{2} \\
\sigma_{2}=\beta \sigma_{\text {eff } 2}+p_{i} \quad \text { Tresca) } \\
A_{2}=\frac{\pi}{4}\left(d_{a}^{2}-d_{i 2}^{2}\right)
\end{gathered}
$$

In (iii) and (iv) are:

$$
\begin{gathered}
\sigma_{\text {eff } 1}=K \phi_{1}^{n} \\
\sigma_{\text {eff } 2}=K \phi_{2}^{n}
\end{gathered}
$$


Where $\mathrm{K}$ and $\mathrm{n}$ are strength factor and strain hardening coefficient of tube material respectively. $\sigma_{\text {eff } 1 \text { is the }}$ stress in the top end section, and $\sigma_{\text {eff } 2}$ stress in the bottom end section .

logarithmic strains at top end section and bottom end section is as follows:

$$
\begin{aligned}
& \phi_{1}=\ln \frac{A_{1}}{A_{0}} \\
& \phi_{2}=\ln \frac{A_{2}}{A_{0}}
\end{aligned}
$$

$A_{0}, A_{1}$, and $A_{2}$ are the original cross sectional area , top end cross sectional area and bottom end cross sectional area respectively. So eqn (i) can be written as:

$$
A_{1}\left(\beta K \phi_{1}^{n}+p_{i}\right)=A_{2}\left(\beta K \phi_{2}^{n}+p_{i}\right)+\pi d_{a} h \mu \sigma_{k}
$$

As COF depends on the value of contact pressure between the tube and the die. We assume, contact pressure is equivalent to the hydroform pressure $\left(\sigma_{k}=p_{i}\right)$.

$$
\mu=\frac{\mu=\frac{\beta K\left(A_{1} \phi_{1}^{n}-A_{2} \phi_{2}^{n}\right)+p_{i}\left(A_{1}-A_{2}\right)}{P_{i} d_{a} \pi h}}{1.15 K\left\{\begin{array}{l}
\left(d_{a}^{2}-d_{i 1}^{2}\right)\left[\ln \left(S_{1}\left(d_{a}-S_{1}\right) / S_{0}\left(d_{a}-S_{0}\right)\right)\right]^{n}- \\
\left(d_{a}^{2}-d_{i 2}^{2}\right)\left[\ln \left(S_{2}\left(d_{a}-S_{2}\right) / S_{0}\left(d_{a}-S_{0}\right)\right)\right]^{n}
\end{array}\right\}+P_{i}\left(d_{i 2}^{2}-d_{i 1}^{2}\right)}
$$

Dimensional data in equation (vi) refer to the Fig.5.and strength factor and strain hardening coefficient can be estimated by experiment.

\subsection{Estimation of hydroform pressure}

\section{RESULTS AND DISCUSSION}

A. Analytical Results.

Using the above derived formula in equations (23) and (24) one can find the value of hydroform pressure required in hydroforming. Now geometrical parameters of our casestudy are shown in Table 1.

Table 1: Values of Geometrical Parameter of tube considered for Case Study

\begin{tabular}{|l|l|l|l|l|}
\hline Sr No & Symbol & Description & Value & Unit \\
\hline 1 & $t_{i}$ & Instantaneous thickness of tube & 3.7 & $\mathrm{~mm}$ \\
\hline 2 & $d_{i}$ & Instantaneous Diameter of tube( outer) & 115 & $\mathrm{~mm}$ \\
\hline 3 & $t_{0}$ & Original Thickness & 5 & $\mathrm{~mm}$ \\
\hline 4 & $d_{0}$ & Original Diameter of tube(Outer) & 70 & $\mathrm{~mm}$ \\
\hline 5 & $\mathrm{k}$ & Strength Factor & 671 & $\mathrm{MPa}$ \\
\hline 6 & $\mathrm{n}$ & Strain Hardening Coefficient & 0.237 & \\
\hline 7 & $L_{0}$ & Original Length of Tube & 180 & $\mathrm{~mm}$ \\
\hline 8 & $L_{i}$ & Instantaneous length of tube & 145 & $\mathrm{~mm}$ \\
\hline 9 & $\varepsilon_{1}$ & Tangential Strain & 0.4964 & \\
\hline 10 & $\varepsilon_{2}$ & Radial Strain & -0.2802 & \\
\hline 11 & $\varepsilon_{3}$ & Axial Strain & -0.2162 & \\
\hline 12 & $\beta$ & Strain ratio & -0.4356 & \\
\hline 13 & $\alpha$ & Stress ratio & 0.0823 & \\
\hline
\end{tabular}


In this section the value of hydroform pressure is determined using Microsoft Excel for different thicknesses of tube using derived formulae in above section for hydroform pressure and instantaneous thickness. The dependence of hydroform pressure on tube thickness is shown in Table 2.

Table 2: Dependence of Hydroform pressure on Tube Original Thickness

\begin{tabular}{|l|l|l|}
\hline Sr No & $\begin{array}{l}\text { Original Tube } \\
\text { Thickness }(\mathrm{mm})\end{array}$ & $\begin{array}{l}\text { Hydroform pressure } \\
(\mathrm{MPa})\end{array}$ \\
\hline 1 & 4.5 & 36.65 \\
\hline 2 & 4.6 & 37.51 \\
\hline 3 & 4.7 & 38.36 \\
\hline 4 & 4.8 & 39.22 \\
\hline 5 & 4.9 & 40.08 \\
\hline 6 & 5 & 40.94 \\
\hline 7 & 5.1 & 41.81 \\
\hline 8 & 5.2 & 42.67 \\
\hline 9 & 5.3 & 43.54 \\
\hline 10 & 5.4 & 44.41 \\
\hline 11 & 5.5 & 45.28 \\
\hline
\end{tabular}

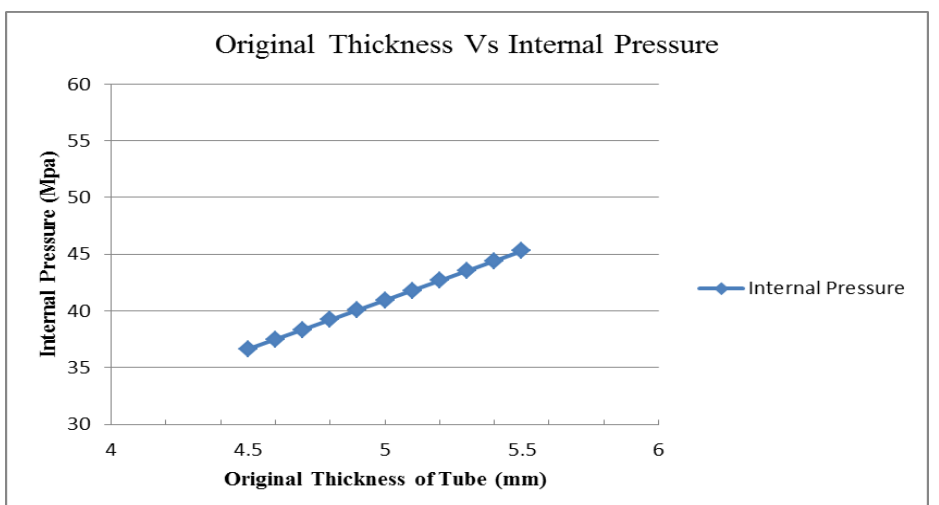

Fig.7. Variation of hydroform pressure with original thickness of tube

From Fig.7 it is seen that hydroform pressure required for hydroforming process vary with original tube thickness. The hydroform pressure is linearly dependent on original tube thickness. From Fig.7. for tube thickness $4.5 \mathrm{~mm}$ value of hydroform pressure is $36.65 \mathrm{MPa}$ and for tube thickness $5.5 \mathrm{~mm}$ valueof hydroform pressure is $45.28 \mathrm{MPa}$

\subsection{Estimation of coefficient of friction (COF)}

\section{A. Analytical Results}

Using the above derived formula for the COF in tube hydroforming, one can find the value of $\mu$ (Provided others geometrical parameters are known to us).Now geometrical parameters of our case study are given in Table 3 .

Table 3: Values of Geometrical Parameter of tube considered for Case Study

\begin{tabular}{|l|l|l|l|}
\hline Sr .No & Symbol & Description & Value \\
\hline 1 & $S_{0}$ & Initial wall thickness & $5 \mathrm{~mm}$ \\
\hline 2 & $S_{1}$ & wall thickness at the side of movable punch & $6 \mathrm{~mm}$ \\
\hline 3 & $S_{2}$ & wall thickness at the side of fixed punch & $1 \mathrm{~mm}$ \\
\hline 4 & $d_{a}$ & Initial outer diameter of the tube & $70 \mathrm{~mm}$ \\
\hline 5 & $d_{i}$ & Initial inner diameter of the tube & $65 \mathrm{~mm}$ \\
\hline 6 & $d_{i 1}$ & Final inner diameter of the tube at the side of movable punch, & $66 \mathrm{~mm}$ \\
\hline 7 & $d_{i 2}$ & Final inner diameter of the tube at the side of fixed punch & $68 \mathrm{~mm}$ \\
\hline 8 & $h_{0}$ & Initial height & $180 \mathrm{~mm}$ \\
\hline 9 & $h$ & Final height. & $145 \mathrm{~mm}$ \\
\hline 10 & $n$ & Strain hardening exponent & 0.237 \\
\hline 11 & $\beta$ & Tresca Coefficient & 1.15 \\
\hline 12 & $\mathrm{k}$ & Strength Factor & 671 \\
\hline
\end{tabular}


For estimation of COF, we assume contact pressure can be to equal to the inner pressure $\left(\sigma_{k}=p_{i}\right)$.So using above assumption and values from above table eqn.6 gives value of coefficient of friction $\mu$ Different values of hydroform pressure are as follows.

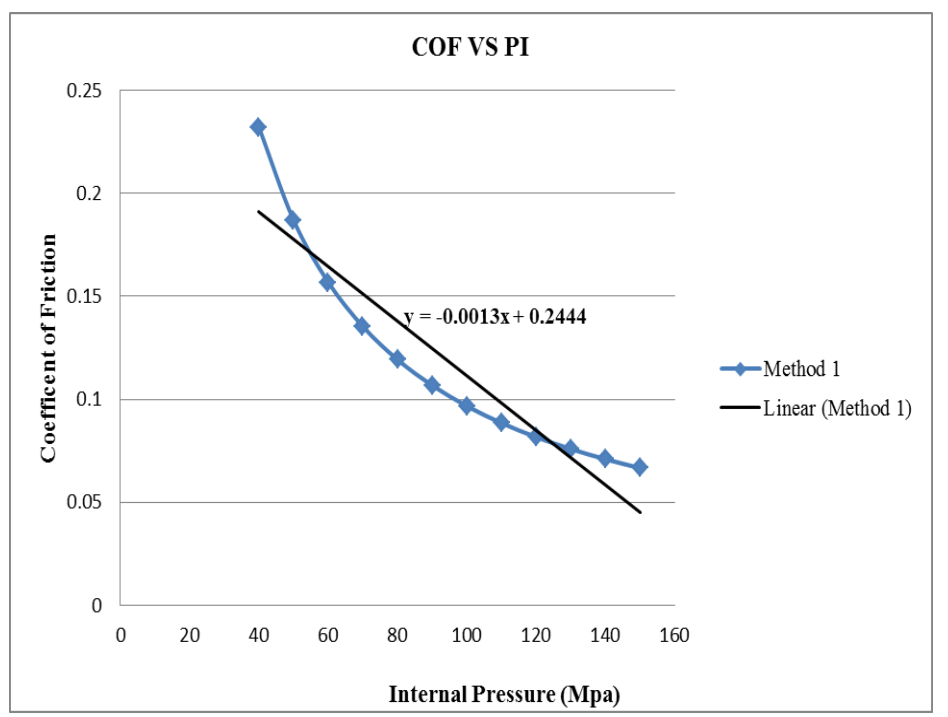

Fig.8: Dependance of hydroform pressure and coefficient of friction

Table 4: Dependence of Hydroform pressure on coefficient of friction

\begin{tabular}{|l|l|l|}
\hline $\begin{array}{l}\text { Sr. } \\
\text { No. }\end{array}$ & Hydroform pressure (MPa) & $\begin{array}{l}\text { Coefficient } \\
\text { of Friction }\end{array}$ \\
\hline 1 & 40 & 0.232011805 \\
\hline 2 & 50 & 0.186929641 \\
\hline 3 & 60 & 0.156874865 \\
\hline 4 & 70 & 0.135407168 \\
\hline 5 & 80 & 0.119306395 \\
\hline 6 & 90 & 0.106783572 \\
\hline 7 & 100 & 0.096765313 \\
\hline 8 & 110 & 0.088568556 \\
\hline 9 & 120 & 0.081737925 \\
\hline 10 & 130 & 0.07595816 \\
\hline 11 & 140 & 0.071004077 \\
\hline 12 & 150 & 0.066710537 \\
\hline
\end{tabular}

From Fig. 8 it is observed that as hydroform pressure is increases coefficient of friction between tube and die surface deacreases. Fig. 8 shows that the COF is inversely proportional to hydroform pressure. For hydroform pressure $50 \mathrm{MPa}$ Value of $\mathrm{COF}$ is 0.1869 and for hydroform pressure $150 \mathrm{MPa}$ value of COF is 0.066 .

\section{B. Numerical results}

Using MATLAB R2013 software the coefficient of friction for the pressure range from $40 \mathrm{MPa}$ to $150 \mathrm{MPa}$ is shown in Table.5

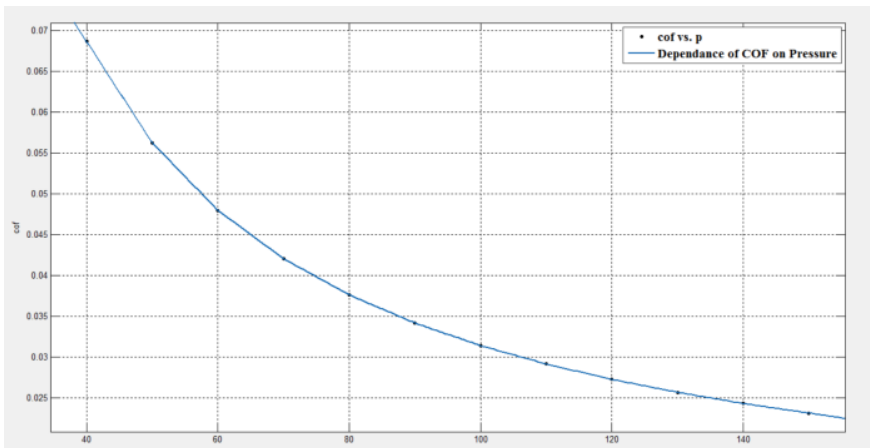

Fig. 9: Dependance of Hydroform pressure and coefficient of friction 
Table 5: Dependence of Hydroform pressure on coefficient of friction

\begin{tabular}{|l|l|l|}
\hline Sr No. & Hydroform pressure $(\mathrm{MPa})$ & COF \\
\hline 1 & 40 & 0.068694 \\
\hline 2 & 50 & 0.056275 \\
\hline 3 & 60 & 0.047996 \\
\hline 4 & 70 & 0.042083 \\
\hline 5 & 80 & 0.037648 \\
\hline 6 & 90 & 0.034198 \\
\hline 7 & 100 & 0.031438 \\
\hline 8 & 110 & 0.029180 \\
\hline 9 & 120 & 0.027299 \\
\hline 10 & 130 & 0.025707 \\
\hline 11 & 140 & 0.024342 \\
\hline 12 & 150 & 0.023159 \\
\hline
\end{tabular}

From Fig.9 it is observed that as hydroform pressure is increases coefficient of friction between tube and die surface decreases. Fig.9 shows that the COF is inversely proportional to hydroform pressure. For hydroform pressure $50 \mathrm{MPa}$ Value of COF is 0.056275 and for hydroform pressure $150 \mathrm{MPa}$ value of COF is 0.023159 . so the nature of curve is same as of curve obtain from MS Excel.

\section{CONCLUSION}

Mathematical model for hydroform pressure and tube hydroforming is studied and implemented to available manufactured of T-Shape tube hydroformed part.It is observed that as tube thickness is increasing the amount of hydroform pressure required for tube hydroforming process also increases. It is observed that as hydroform pressure increases the coefficient of friction between tube and and die surface decreases.

\section{REFERENCES}

[1] M. Koc ,T. Altan,An overall review of the tube hydroforming (THF) technology, Journal of Materials Processing Technology 108(3),2001, 384-393

[2] N. Asnafi ,A. Skogsgardh ,Theoretical and experimental analysis of stroke controlled tube hydroforming, Journal of materials Science and engineering, A279,2000,95-110

[3] B.Sreenivasulu1, G. Prasanthi, T. Naresh Kumar, Simulative Analysis Of Tube Hydroforming Process", International Journal of Research in Engineering and Technology ,2 (11),2013,756-763

[4] M. Plancak,, F. Vollertsen, J. Woitschig, Analysis, finite element simulation and experimental investigation of friction in tube hydroforming ,Journal of Materials Processing Technology 170,2005,220-228.

[5] M.Mizumura, O. Honda, T.Yoshida, K. Iguchi , Y. Kuriyama,Development of Hydroforming Technology, Nippon Steel Technical Report No:-90, 2004,116-121

[6] M. Plancak,, F.Vollertsen, J.Woitschig,Analysis, finite element simulation and experimental investigation of friction in tube hydroforming “,Journal of Materials Processing Technology, 170,2005, 220-228.

[7] Gang Liu, Shijian Yuan, Bugang Teng, Analysis of thinning at the transition corner in tube hydroforming, Journal of Materials Processing Technology 177,2006, 688-691

[8] J. Abrantes , C. Eduardo Celia De Lima , G. F. Batalha ,Numerical Simulation of an aluminium alloy tube hydroforming, Journal of Materials Processing Technology 179,2006, 67-73

[9] H. Orban, S. J. Hu ; Analytical modelling of wall thinning during corner filling in structural tube hydroforming , Journal of Materials Processing Technology ;194,2007,7-14.

[10] A. Kocańda , H. Sadłowska, Automotive Component Development By Means Of Hydroforming, 8(3 ), 2008,55-72.

[11] Edina Karabegovic , Milan Jurkovic, Isak Karabegovic " Analytical Modeling of Axial Force in Hydroforming of Thin-Walled Tube Elements .”,International Journal of Engineering and Technology,2(9), 2012. 